Bio Core

Exploring Scientific Community
International Journal of Nutritional Science and Food Technology

\title{
Acute undernutrition (Wasting) and Associated Factors among Children aged 6-23 Months in Kemba Woreda, Southern Ethiopia: A community based Cross-Sectional Study
}

Eskezyiaw Agedew, Assegedew Shimeles

Arba Minch University, Southern Ethiopia

*Corresponding Author: Eskezyiaw Agedew, Arba Minch University, Southern Ethiopia, E-mail: esk1agid@gmail.com

Citation: Eskezyiaw Agedew, Assegedew Shimeles (2016) Acute undernutrition (Wasting) and Associated Factors among Children aged 6-23 Months in Kemba Woreda, Southern Ethiopia: A community based Cross-Sectional Study. Int J Nutr Sci \& Food Tech 2:2, 59-66.

Copyright: (c) 2016 Eskezyiaw Agedew et al. This is an open-access article distributed under the terms of the Creative Commons Attribution License, which permits unrestricted use, distribution, and reproduction in any medium, provided the original author and source are credited.

Received August 10, 2016; Accepted September 20, 2016; Published September 30, 2016.

\section{Abstract}

Background: wasting is a major health problem in developing countries. Wasting (low in weight- for- age of $<-2 \mathrm{Z}$-score) is affecting significant number of children in the world and responsible for loss of many child lives particularly in Asian and sub-Saharan countries. Identifying potential factors and forecasting appropriate intervention strategies plays vital role in declining child mortality.

\section{Objective}

To assess acute undernutrition (wasting) and associated factors among Children aged 6-23 Months in Kemba Woreda, Southern Ethiopia.

\section{Methods}

Community based cross-sectional study was carried out among 562 mothers who have young child from 6-23 months in 2014/15 in Kemba Woreda by using pre tested and structured questioners. Multivariate analyses were conducted by SPSS version 20.

\section{Results}

The prevalence of wasting was found to be $21 \%$ with $95 \%$ CI (17.2-23.9). In multiple logistic regressions, boys[AOR: $1.8 ; 95 \%$ $\mathrm{CI}(1.17-2.81)$ ], maternal age > 30years [AOR: 2.60; 95\% CI(1.07-6.35)], mothers who have no formal education [AOR: $2.76 ; 95 \%$ $\mathrm{CI}(1.63-4.69)$ ], mothers who work as daily workers [AOR: 3.06; 95\% $\mathrm{CI}(1.03-9.12)$ ] and have Private work activity(merchant, farmers) [AOR: 2.39; 95\% CI(1.61-3.53)],mothers who have no antenatal and post natal follow up [AOR: 2.33; 95\% CI(1.45-3.74)], [AOR: 1.82; 95\% CI(1.02-3.25)] respectively, non-exclusive breastfed children [AOR: 2.18; 95\% CI(1.20-3.99)] and media exposure of the mother[AOR: 1.99;95\% CI(1.19-3.32)] were identified as significant independent predictors of childhood acute under-nutrition. However, medical illness of children and immunization status were not associated with wasting.

Conclusion and Recommendation

A great proportion of children were affected by acute nutritional insult. Significant numbers of factors were found to be having statistical association with wasting. An organized effort should be made at all levels to increase maternal awareness and strengthening on practice of exclusive breastfeeding, proper antenatal and post natal care provision to solve the high level of acute under-nutrition in children.

Key words: wasting, children, Kemba, South Ethiopia 


\section{Introduction}

Undernutrition results most commonly from limited quality or quantity of food, suboptimal feeding practices, and high rates of infectious diseases. It is found in the form of either wasting, which is usually considered to be a short-term (i.e., acute) response to inadequate intake or an infectious disease episode, or stunting that is considered to be a longer-term response to a sustained poor dietary intake or repeated illnesses[1].

Worldwide, of the 80 countries with available data, 23 have levels of wasting (i.e., weight-for-height below -2SD) greater than 10 per cent. While a significant number of the world's 52 million wasted children live in countries where cyclical food insecurity and protracted crises exacerbate their vulnerability, the majority reside in countries not affected by emergencies. In these countries factors such as frequent incidence of infectious diseases, inadequate caring capacity and social and cultural practices are the major factors that need to be addressed to reduce wasting. Moderate and severe wasting represents an acute form of undernutrition, and children who suffer from it face a markedly increased risk of death. More than 29 million children under 5 , an estimated 5 per cent, suffered from severe wasting $[2,3]$.

Undernutrition puts children at far greater risk of death and severe illness due to common child-hood infections, such as pneumonia, diarrhea, malaria, HIV and AIDS and measles. A child who is severely under-weight is nearly 10 times more likely to die of diarrhea than a child who is not. Moreover, undernutrition not only weakens the immune system, putting children at higher risk of more severe, frequent and prolonged bouts of illness and it may further worsen the child's nutritional status at a time of greater nutritional needs but also decrease mental development and cognitive achievement. This interaction between undernutrition and infection creates a potentially lethal cycle of worsening illness and deteriorating nutritional status. Critical nutrition interventions that break this cycle include promoting optimal breastfeeding practices, encouraging micronutrient supplementation and reducing the incidence of low birth weight[3].

Ethiopia is the seventh wasting burden country from the ten most affected countries. The nationwide magnitude of wasting is almost $10 \%[3,4]$. Some studies conducted in different parts Ethiopia shows that significant numbers of children are suffering from wasting ([5, 6]. In contrast Ethiopia is one the nation known by implementing both nutrition specific and nutrition sensitive intervention strategies of infant and child feeding guideline developed by WHO in 2004 Due to the high prevalence of inappropriate child feeding practices and the importance of exclusive breastfeeding. Since then, varying levels of interventions, giving due emphasis to key messages on complementary feeding, were being given both at health institution and community level to meet the Millennium Development Goals' (MDGs).Nonetheless, these efforts were not based on organized evidence on the level of existing practices [7].
However, little information is available on factors associated with wasting, or acute malnutrition. In this study, we tried to determine the extents of factors that could lead to acute undernutrition in children. Therefore, the aim of this study was to have detailed and concrete data that fill these gaps and would add a value that directs policy makers to draw appropriate intervention measures to improve and flourish the health of future generation.

\section{Methods and Materials}

\section{Study Setting and Source population}

This community based cross-sectional study was carried out in 2014/15 on 562 mothers who has young child from 6 months to 23 months of age in Kemba Woreda located in Southern parts of Ethiopia. The Southern Nations Nationalities and People's Regional State (SNNPRS) consists of 13 zones and 104 woredas. The region has an estimated $15,042,531(20.4 \%$ of the national estimate) people. Close to $90 \%$ of the population are estimated to be rural inhabitants, while $1,545,710$ or $10.3 \%$ are urban. Kemba woreda is one of the administrative woreda in Gamo Gofa Zone, South Ethiopia $100 \mathrm{kms}$ away from Zonal town Arba Minch. From the total population around 44,000 are women in reproductive age group. The Health institution distribution in the woreda is 39 health posts and 9 health centers providing health services including maternal and child health care.

\section{Inclusion and Exclusion criteria}

Mothers/care givers who have young children from 6 to 23 months of age who live in the selected Keble for at least 6 months were included in the study and those who had mental illnesses interfering the interview were not considered in study.

\section{Sample size determination and Sampling Technique}

The sample size was determined by using single population proportion formula by the following assumption for prevalence of wasting (P) as 13\% in Gambella region[4], 4\% as degree of precision and with $95 \%$ of confidence interval

$$
\mathrm{n}=\frac{\left(\frac{z}{2} \alpha\right)^{2} p(1-p)}{d^{2}}
$$

The final sample size was calculated by taking 2 as design effect and $5 \%$ none response rate which is 569 . The sample size for the second objective was also calculated by using Epi-info version 7 for cross sectional study by taking in to account of different factors affecting the level of wasting from previous studies but the results were less than the sample size obtained above and finally the $\operatorname{maximum}(\mathrm{n}=569)$ was taken.

\section{Sampling Procedure}

From 39 small Keble in the woreda six Kebele was selected by using lottery method. Then the number of study participant was allocated for each Kebele based on proportional to size allocation methods by using community based demographic and health 
related information registration prepared by Health Extension workers as the sampling frame. Rapid censuses were conducted first to identify the target house hold. Finally infant-mother pairs were selected from each Keble by using systematic sampling technique after giving code for each household which has young child from six to 23 months (figure 1 ).

\section{Data collection method, measurement and quality control}

Data were collected from Mothers/care givers who have one child in age 6 to 23 months from each household by direct interviewing. Pre-tested structured questionnaire adapted from different literature was used to collect socio-demographic and

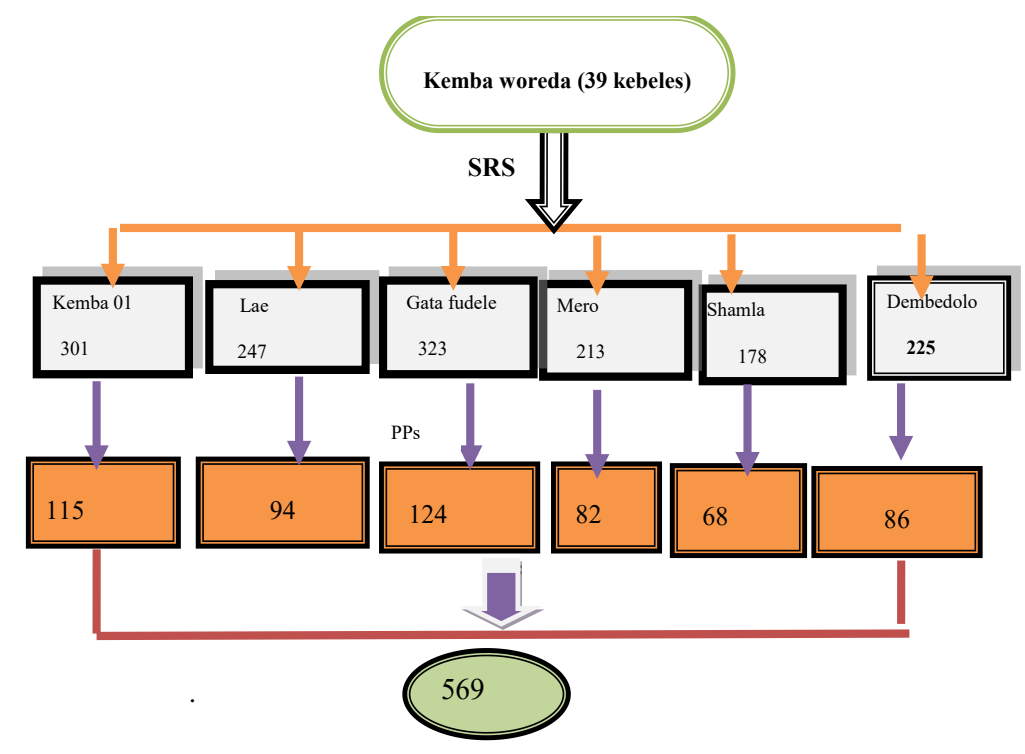

Fig 1. Schematic presentation of sampling procedure in Kemba Woreda, South west Ethiopia, 2015

others variables. First the questionnaire s was prepared in English and translated to Amharic and pre tested on $5 \%$ of mothers before actual data collection outside the selected kebeles; correction and modification was done based on the gap identified during interview. Six grade 12 completed students were recruited as data collectors and supervised by 3 Nurses. Three day training was given on the aim of the research, content of the questionnaire, and how to conduct interview for data collectors and supervisor to increase their performance in field activities. The Collected data were checked every day by supervisors and principal investigator for its completeness and consistency.

Anthropometric measurements were also taken after making proper adjustment or standardization of instruments. The weight of each child was taken by using digital scale wearing light cloth, checking the calibration using $2 \mathrm{~kg}$ rod during each instant of weight measuring and the measurement was approximated to the nearest $10 \mathrm{~g}$. Sliding board was used to measure the length of children in recumbent position by two data collectors and taken to the nearest $1 \mathrm{~mm}[8,9]$. The data collectors were trained efficiently on how to take the anthropometric measurements.

\section{Data analysis and Management}

Data was coded and entered in to Epi-Info version 3.5.1 and exported to SPSS Version 20 for analysis. Exploratory data analysis was done to check missing values, potential outliers and the normality distribution for those continuous variables. The presence of multi- collinearity also was checked and effort was made to incorporate different models to cross check. Anthropometric index (WHZ) was analyzed by using WHO Anthro software version 3.2.2 and categorized as wasted if $\mathrm{WHZ}<-2 \mathrm{Z}$ score and as normal if $\mathrm{WHZ}$ $>-2 \mathrm{Z}$ score. Extreme outlier of $<-5 \mathrm{Z}$ score of WFL was omitted from the analysis. Descriptive Frequencies were calculated to describe the study population in relation to relevant variables. Bivariate logistic regression analysis was calculated to assess the crude association between dependent and independent variables. Finally Variables which shows association in bivariate logistic regression analysis and have P-value less than 0.25 entered in to Multivariate logistic regression model, to identify significant independent predictors of wasting and to control the possible effect of confounding. Significant factors were considered at P-value less than 0.05 .

\section{Ethical consideration}

Ethical clearance was obtained from Research ethics committee (REC) of Addis continental institute of Public Health. Permission letter was obtained from Kemba Woreda Health office. Verbal informed consent from each study participant was obtained after clear explanation about the purpose of the study. All the study participants were reassured that only anonymous data were taken. They were given the chance to ask anything about the study and made free to refuse or stop the interview at any moment they want if that was their choice. 


\begin{tabular}{|c|c|c|}
\hline Variables & Frequency & Percent $(\%)$ \\
\hline $\begin{array}{l}\text { Age of child } \\
\text { 6-8 months } \\
\text { 9-12 months } \\
\text { 13-17 months } \\
18-24 \text { months }\end{array}$ & $\begin{array}{l}125 \\
172 \\
119 \\
146\end{array}$ & $\begin{array}{l}22.2 \\
30.6 \\
21.2\end{array}$ \\
\hline $\begin{array}{l}\text { Sex of child } \\
\text { Male } \\
\text { Female }\end{array}$ & $\begin{array}{l}273 \\
289\end{array}$ & $\begin{array}{l}48.6 \\
51.4\end{array}$ \\
\hline $\begin{array}{l}\text { Residence of mother } \\
\text { Rural } \\
\text { Urban }\end{array}$ & $\begin{array}{l}205 \\
357\end{array}$ & $\begin{array}{l}36.5 \\
63.5\end{array}$ \\
\hline $\begin{array}{l}\text { Age of mother } \\
15-19 \\
20-24 \\
25-30 \\
>=31\end{array}$ & $\begin{array}{l}88 \\
151 \\
271 \\
52\end{array}$ & $\begin{array}{l}15.7 \\
26.9 \\
48.2 \\
9.3\end{array}$ \\
\hline $\begin{array}{l}\text { Religion statues } \\
\text { Orthodox } \\
\text { Protestant } \\
\text { Muslim }\end{array}$ & $\begin{array}{l}197 \\
348 \\
17\end{array}$ & $\begin{array}{l}35.1 \\
61.9 \\
3.0\end{array}$ \\
\hline $\begin{array}{l}\text { Education } \\
\text { No education } \\
\text { Primary Education } \\
\text { Secondary \& above }\end{array}$ & $\begin{array}{l}173 \\
202 \\
187\end{array}$ & $\begin{array}{l}30.8 \\
35.9 \\
33.3\end{array}$ \\
\hline $\begin{array}{l}\text { Occupational statues } \\
\text { Daily laborer } \\
\text { Private(merchant, farmers) } \\
\text { Government worker } \\
\text { Housewife }\end{array}$ & $\begin{array}{l}20 \\
259 \\
27 \\
256\end{array}$ & $\begin{array}{l}3.6 \\
46.1 \\
4.8 \\
45.6\end{array}$ \\
\hline $\begin{array}{l}\text { Ethnicity } \\
\text { Gamo \&Gofa } \\
\text { Wolaita } \\
\text { Amhara } \\
\text { Others }\end{array}$ & $\begin{array}{l}491 \\
58 \\
11 \\
2\end{array}$ & $\begin{array}{l}87.4 \\
10.3 \\
2.0 \\
0.4\end{array}$ \\
\hline
\end{tabular}

Table 1.Socio-demographic Characteristics of mothers, who had infant aged from 6 months to 23, who live in Kemba Woreda, 2014/15 


\section{Result}

Socio-demographic characteristics of the mothers and young child

A total of 562 women having young child aged 6 to 23 months were interviewed in the study from 569 sampled mothers with $98.77 \%$ response rate. The mean age of children were 13.82 months \pm $5.85(\mathrm{SD})$ and $53 \%$ were found in age range from 6 months to 1 years and 273(48.6\%) were male and 289(51.4\%) were female. About one third $(30.8 \%)$ of respondents were having no formal educational and about half $(46.1 \%)$ of them were farmers and merchants in their occupational statues (Table 1).

\section{Prevalence of acute under nutrition}

From 562 interviewed mothers-child pair 21\%; 95\% CI (17.223.9) of children had global acute malnutrition of which $24.4 \%$; 95\% CI (19.2-29.6.) were boys and 17.1\%; 95\%CI (12.8-21.4) were girls, $13.7 \%$; 95\% CI (10.8-16.6) were moderately wasted and boys were more affected than girls, $17.6 \%$; 95\% CI (13.0$22.2)$ boys and $10.2 \%$; $95 \%$ CI (6.8-13.7) girls had moderate acute malnutrition. The prevalence of severe wasting was $6.8 \% ; 95 \%$

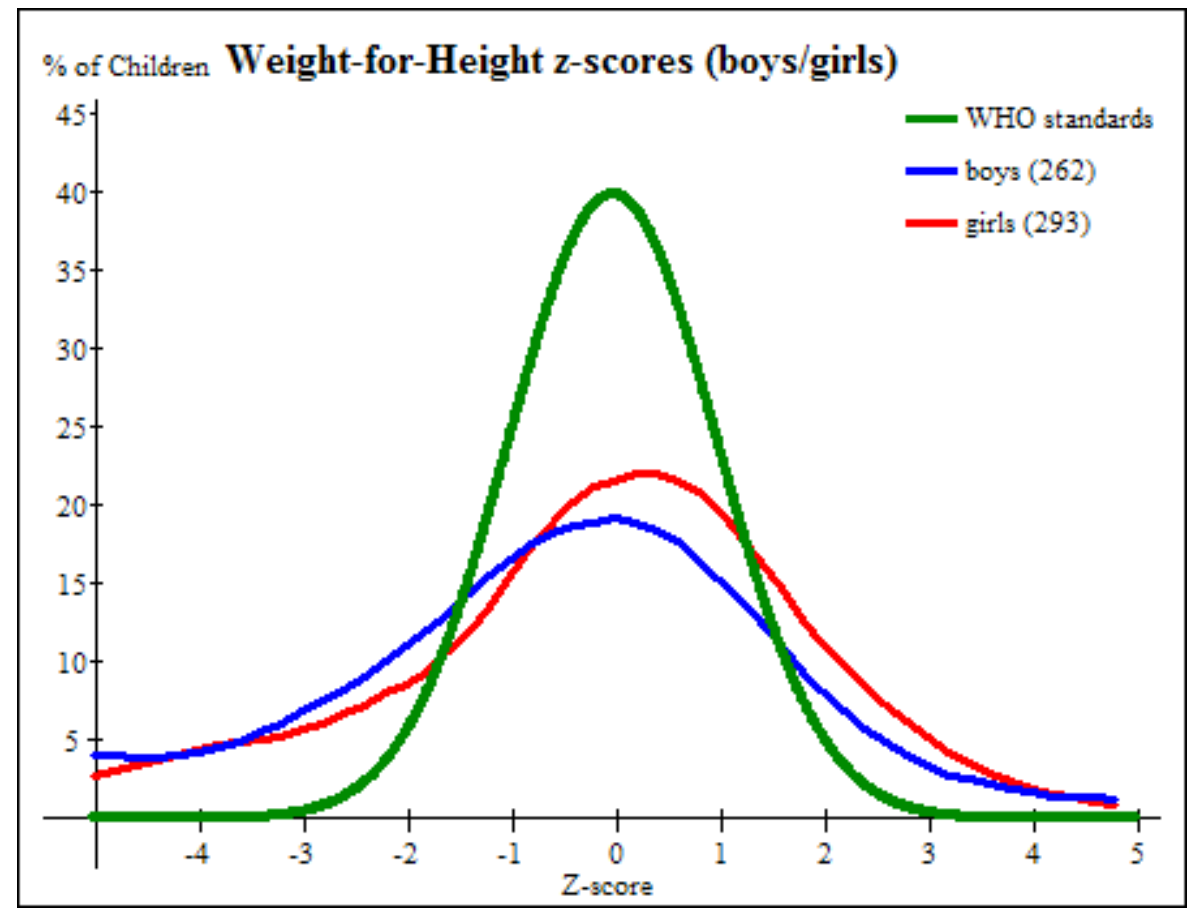

CI (4.7- 8.9) In this case boys were more vulnerable than girls; of boys and of girls were severely malnourished. Mean \pm SD of WHZ was $-0.44 \pm 2.52$ (fig. 2).

\section{Factors associated with acute under nutrition}

After conducting Multivariate logistic regression analysis, boys [AOR: 1.8; 95\% CI(1.17-2.81)], age of mothers those in age group $>=30$ years [AOR: 2.60; 95\% CI(1.07-6.35)], education level those who have no formal education [AOR: 2.76 ; $95 \%$ CI(1.63-4.69)], occupational of mothers those who worked as daily workers [AOR: 3.06; 95\% CI(1.03-9.12)] and Private work activity(merchant, farmers) [AOR: $2.39 ; 95 \% \mathrm{CI}(1.61-3.53)$ ], media exposure of the mother[AOR: $1.99 ; 95 \% \mathrm{CI}(1.19-3.32)]$,children who did not exclusively breastfed [AOR: 2.18 ; 95\% CI(1.20-3.99) and mothers who had no antenatal and post natal care follow up [AOR: 2.33; 95\% CI(1.45-3.74)], [AOR: 1.82; 95\% CI(1.02-3.25)] respectively were significantly associated with acute undernutrition.

International Journal of Nutritional Science and Food Technology An open Access Journal
On the other hand, age of the child, residence, place of delivery, timely introduction of complementary feeding; dietary diversity score and immunization status of children were not identified as predictors of wasting (Table2).

\section{Discussion}

Result of this study showed that the level of acute under-nutrition or wasting (i.e. WHZ<-2SD) was $21 \%$; 95\% CI (17.2-23.9) and found that males $(24.4 \%) ; 95 \%$ CI $(19.2-29.6$.$) were more$ vulnerable population group than females (17.1\%) 95\%CI (12.821.4). The overall prevalence of wasting in this study is much higher than the national prevalence of Ethiopia (10\%), SNNPR $(9.7 \%)$, Nepal (16\%), among orphaned children in Gondar $(9.9 \%)$ $[4,9,10]$ respective, but nearly similar finding were observed in study conducted in north west Ethiopia(17.7\%) and report of regional prevalence of wasting in $\operatorname{Afar}(19.5 \%)$ and Somali(22.2\%) from $\operatorname{EDHS}[4,11]$. The discrepancies may be due to variation in data collection period and the target populations in this study are those children whose nutritional need and feeding practice are 
Eskezyiaw Agedew et al, IJNF 2016, 2:2 Table 2.Factors associated with exclusive breast feeding practice, among mothers who have 6-23 month's young child in Kemba Woreda, 2014/15.

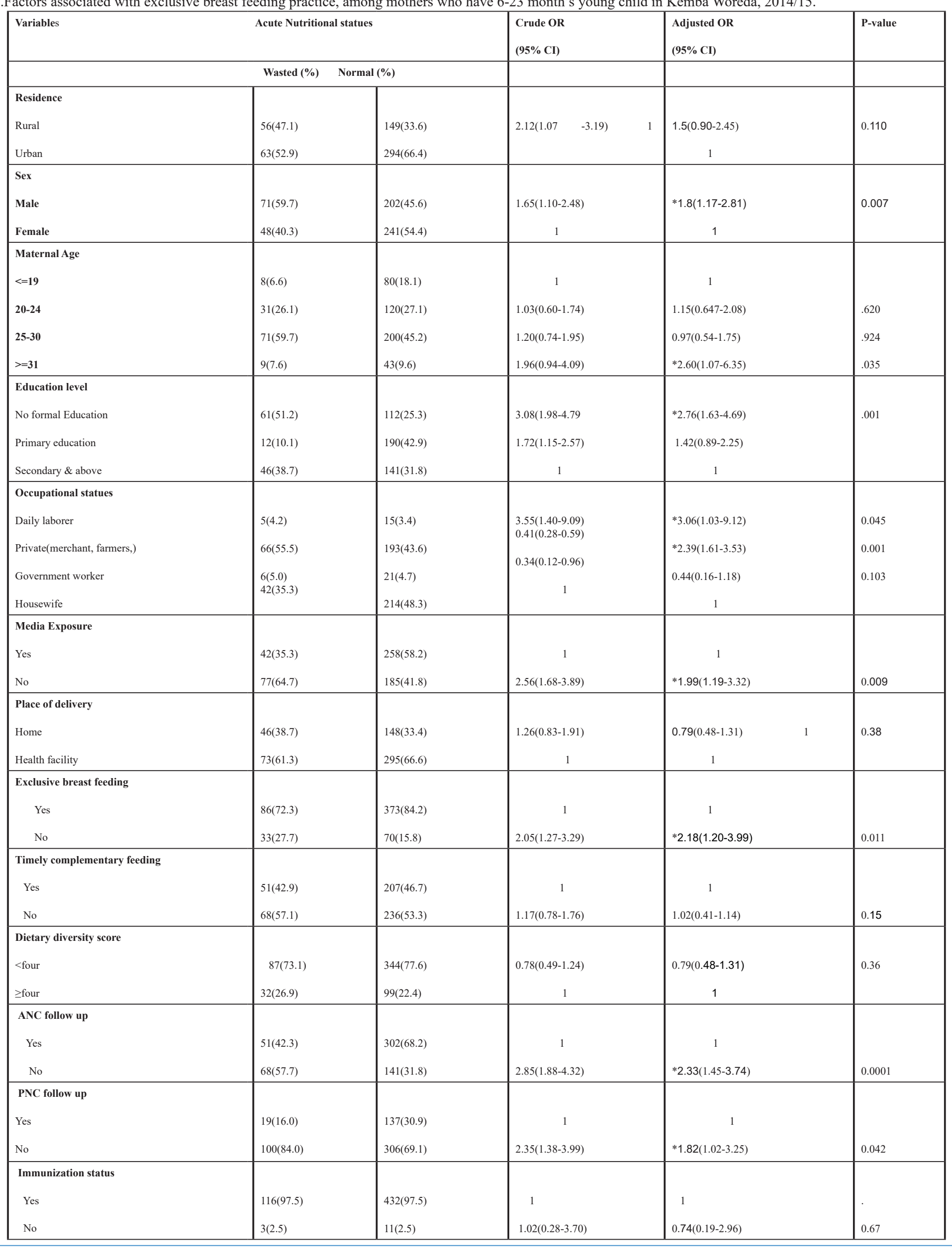

International Journal of Nutritional Science and Food Technology An open Access Journal

Volume 2 Issue 2, September 2016 
relied by their mothers or caregivers. They are prone to nutritional deprivation. Practices of suboptimal breast feeding, untimely inappropriate introduction of complementary feeding may take higher contribution of why the prevalence of wasting is higher in this setting.

The main contributing factors for child wasting or acute undernutrition were being male, maternal age $>30$ years, maternal educational status and occupational status, post natal follow up exclusively breast fed children, maternal media exposure and having antenatal and post natal care follow up. Children born from mothers whose age $>30$ years were nearly 3 times more likely to wasted than those who born from younger mothers. The odds of wasted children in non-exclusively breast fed children was 2 times higher as compared to children who exclusively breastfed. Similarly, children born from mothers with no formal education were almost three times more likely to be undernourished than children born from mothers who have secondary and above education level. This finding is consistent with finding[9, 1214],it shows that improved maternal education enhances mothers knowledge, attitudes and practice towards benefits of exclusive breast feeding practice, and they are the primary responsible body to improve and maintaining better nutritional status of children. In addition, children born from mother who work as daily workers and merchant; and children from mothers who have no post natal care follow up were more likely to be wasted as compared to their counterparts. The findings are almost go in line with findings from north west Ethiopia and Nigeria[9, 13].

\section{Strength and weakness of the study}

The study has strong generalization power as compared with others study conducted with relatively small sample size and institutional based. Recall bias may be introduced even if it was minimized by probing mothers to report by association with different life events may not remember events occurred in the past, and possibility of interviewer bias and misreporting of events were the potential limitation. And the study was also fail to address variables like dietary inadequacy at individual level or portion size estimation, household income status and house hold food security which may have affect our measure of interest.

\section{Conclusion and Recommendation}

A striking figure was observed from the finding. Huge numbers of children were suffering from wasting and can be conclude that prone to various infections and found at greatest risk for childhood mortality. Positive statistically significant associations were identified between acute under-nutrition and exclusive breast feeding, access to information sources, high academic achievement, having occupation and attending antenatal and postnatal care follow up. But, being boy and increased maternal age were negatively associated with wasting. Nutrition education should be highly integrated with other routine health service provisions and especially essential nutrition action should effectively implemented at the grass root level because most of the identified factors are delivered during the six critical contact points as clearly stated from the guideline of IYCF. As a strong recommendation, there should be program evaluation studies that are specifically targeted to direct nutrition intervention towards the management of acute malnutrition at the community level.

\section{Acknowledgment}

We would like to thank Arba Minch University for funding of our research work. Our deepest gratitude goes to data collectors, kebeles leaders and Kemba woreda Health center manager for his cooperation starting from the beginning till the end of data collection time.

Computing interest-The authors declare that they have no computing interest.

\section{Authors' contribution}

EA: Initiated the research, wrote the research proposal, conducted the research, did data entry and analysis and wrote the manuscript. AS: Involved in the write up of methodology of proposal and Manuscript preparation

\section{Abbreviation}

AOR-Adjusted odd ratio, SAM-sever acute malnutrition, MUACMid-upper-arm circumference, CI-confidence interval, SDstandard deviation, TFU- Therapeutic feeding Unit, SNNPR- South nations and nationalities people's region of Ethiopia, IYCF-infant and young child feeding.

\section{Reference}

1. Stephanie A. Richa rd, Robert E. Black, and R.H. Gilman (2012) Wasting Is A ssociated with S tunting in Early Childhood. The Journa 1 of Nutrit ion, 142 p. 1291-1296.

2. United Nations Children's Fund, W.H.W., The World Bank, Levels \& Trends in Child Malnutrition;UNICEF-WHO-The World Bank Joint Child Malnutrition Estimates 2012.

3. UNICEF, IMPROVING CHILD NUTRITION; The achievable imperative for global progress. 2013.

4. Macro, C.S.A.E.a.O.,(2011) Ethiopia Demographic and Health Survey. Addis Ababa, Ethiopia and Calverton, Maryland,USA: Central Statistical Agency and ORC Macro.

5. Motee A, D.R.D., Pugo-Gunsam P,and Rajesh Jeewon (2013) An Assessment of the Breastfeeding Practices and Infant Feeding Pattern among Mothers in Mauritius. Journal of Nutrition and Metabolism.

6. Kimani-Murage WE, M.J., Fotso C, Kyobutungi C, Mutua 
KM,Gitau MT (2011) Patterns and determinants of breastfeeding and complementary feeding practices in urban informal settlement, Nairobi Kenya. BMC Public Health.

7. Health, F.M.o., (2004) National strategy for Infant and Young Child Feeding (IYCF). Ethiopia: Federal Ministry of Health, Family Health Department.

8. WHO, WHO Multicenter Growth Reference Study Group WHO Child Growth Standards: Length/ height-for-age, weight-for-age, weight-forlength, weight-for-height and body mass index-for-age: Methods and development. Geneva, World Health WHO. 2006.

9.Gultie, T., E. Sisay, and G. Sebsibie, (2014) Nutritional status and associated factors among orphan children below the age of five years in Gondar City, Ethiopia Journal of Food and Nutrition Sciences, 2(4): p. 179-184.

10.Bhandari, T.R. and M. Chhetri, (2013) Nutritional Status of Under Five Year Children and Factors Associated in Kapilvastu
District, Nepal. Journal of Nutritional Health \& Food Science, 1: p. 6.

11.Edris, M.,(2007) Assessment of nutritional status of preschool children of Gumbrit, North West Ethiopia Ethiop.J.Health Dev.21(2): p. 125-129.

12.Charmaine S, M.J., Dibley and Kingsley E.(2010) Complementary feeding indicators and determinants of poor feeding practices in Indonesia: a secondary analysis of 2007,Demographic and Health Survey data. Public Health Nutrition:

13.Akorede, Q.J., O.M. Abiola, (2013) and ASSESSMENT OF NUTRITIONAL STATUS OF UNDER FIVE CHILDREN IN AKURE SOUTH LOCAL GOVERNMENT, ONDO STATE, NIGERIA IJRRAS, 14 (3).

14.Egata, G., Y. Berhane, and A. Worku,(2014) Predictors of acute $u$ ndernutr it io $n$ among children aged 6 to 36 months in east rural Ethiopia. BMC Pediatrics, 14: p. 91. 